\title{
Temperature conditions in the RBMK spent fuel pool in the event of disturbances in its cooling mode ${ }^{*}$
}

\author{
Dadid A. Hakobyan ${ }^{1}$, Victor I. Slobodchuk ${ }^{2}$ \\ 1 National Research Nuclear University MEPhI, 31 Kashirskoe Hwy, 115409 Moscow, Russia \\ 2 Obninsk Institute for Nuclear Power Engineering, NRNU MEPhI, 1 Studgorodok, 249040 Obninsk, Kaluga Reg., Russia \\ Corresponding author: Victor I. Slobodchuk (slobovic@mail.ru)
}

Academic editor: Yury Korovin • Received 28 May 2019 • Accepted 10 January 2021 Published 24 March 2021

Citation: Hakobyan DA, Slobodchuk VI (2021) Temperature conditions in the RBMK spent fuel pool in the event of disturbances in its cooling mode. Nuclear Energy and Technology 7(1): 9-13. https://doi.org/10.3897/nucet.7.64363

\begin{abstract}
The problems of reprocessing and long-term storage of spent nuclear fuel (SNF) at nuclear power plants with RBMK reactors have not been fully resolved so far. For this reason, nuclear power plants are forced to search for new options for the disposal of spent fuel, which can provide at least temporary SNF storage. One of the possible solutions to this problem is to switch to compacted SNF storage in reactor spent fuel pools (SFPs). As the number of spent fuel assemblies (SFAs) in SFPs increases, a greater amount of heat is released. In addition, no less important is the fact that a place for emergency FA discharging should be provided in SFPs. The paper presents the results of a numerical simulation of the temperature conditions in SFPs both for compacted SNF storage and for emergency FA discharging. Several types of disturbances in normal SFP cooling mode are considered, including partial loss of cooling water and exposure of SFAs. The simulation was performed using the ANSYS CFX software tool. Estimates were made of the time for heating water to the boiling point, as well as the time for heating the cladding of the fuel elements to a temperature of $650{ }^{\circ} \mathrm{C}$. The most critical conditions are observed in the emergency FA discharging compartment. The results obtained make it possible to estimate the time that the personnel have to restore normal cooling mode of the spent fuel pool until the maximum temperature for water and spent fuel assemblies is reached.
\end{abstract}

\section{Keywords}

Nuclear power plant, reactor, spent fuel pool, spent nuclear fuel, temperature conditions

\section{Introduction}

The life of the operating RBMK-1000 units and the existing storage conditions for spent nuclear fuel (SNF) at NPP sites require that the number of SNF storage sites should be increased. One of the possible temporary solutions to this problem is to switch to compacted SNF storage in reactor spent fuel pools (SFPs). The amounts of fuel stored in the SFP are increased by transferring SFAs to non-canis- ter compacted storage. Owing to this, between the beams of the SFP slotted overlap, it is possible to place 2.4 times more SFAs than in standard (canister) fuel storage. However, as the number of SFAs in the SFP increases, so does the amount of heat released by them. In this regard, it becomes necessary to carry out thermohydraulic calculations of the SFPs in order to substantiate the safety of compacted SNF storage. In addition, it is required that a place for emergency FA unloading should be provided in the SFP. 
The SFPs are resistant to emergency situations: because of their stable structure severe accidents in them have long been considered as unlikely events in which the operators will have enough time to take adequate corrective actions. The Fukushima Daiichi nuclear disaster, which followed the earthquake in Japan on March 11, 2011, renewed interest in the safety of SNF stored in SFPs during loss-of-coolant accidents (LOCAs) (Bernd 2015; Song and Kim 2014).

In general, there are four different thermohydraulic scenarios that can arise during LOCAs in SFPs:

- fuel assemblies are completely covered with water;

- partially exposed but undamaged SFAs;

- partially exposed but damaged SFAs; and

- completely exposed SFAs (Kaliatka et al. 2013).

When the SFP normal cooling system is inoperative, heat is removed from the SFAs due to natural convection of water and air and is dissipated into the environment. Evaporation can also play a significant role as the water temperature rises (Kaliatka et al. 2013; Partmann et al. 2018; ChengLun 2018; Hung et al. 2013; Wang et al. 2012).

If the water level in the pool is lower than the upper part of a spent fuel assembly, this does not necessarily lead to immediate heating of its exposed part. As long as the water level is not much lower than the upper part of the SFA, the exposed part can be cooled by the steam flow and the rise in the water level due to its boiling in the lower part. The calculations carried out in (Gauntt et al. 2000) assume that the cladding temperature peak in the exposed part of the fuel assemblies can be $<800 \mathrm{~K}$, even when the water surface drops $1.5-2.0 \mathrm{~m}$ below the upper part of the SFAs. Nevertheless, it should be recognized that the thermohydraulic phenomena occurring when the SFAs are partially exposed are complex (Barto et al. 2013; Chen et al. 2014; Ahn et al. 2016; Ogino 2012; Jäckel 2013; Cheng-Lun 2018).

This paper considers the following scenarios:

- computational analysis of the thermal hydraulics of the SFP model during the compacted SNF storage in the event of disturbances in the SFP normal cooling conditions; and

- computational analysis of the temperature conditions in the SFP compartment, into which emergency SFA discharging is provided, in the event of disturbances in the SFP normal cooling conditions.

A study was carried out concerning modes with the termination of the SFP cooling and with partial loss of cooling water in the SFP with the exposure of SFAs by 20,25 and $50 \%$.

\section{Computational model}

Figures 1 and 2 show the layout of SFAs in the SFP during compacted SNF storage (Fig. 1) and during emergency discharging (Fig. 2).

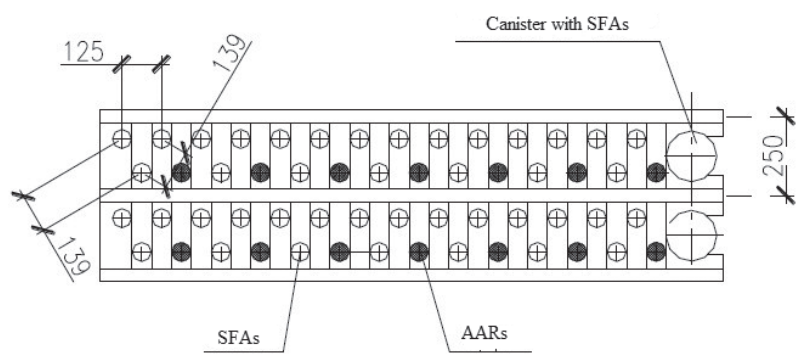

Figure 1. Layout of non-canister SFA placement in the SFP. $\mathrm{AAR}=$ additional absorber rods.

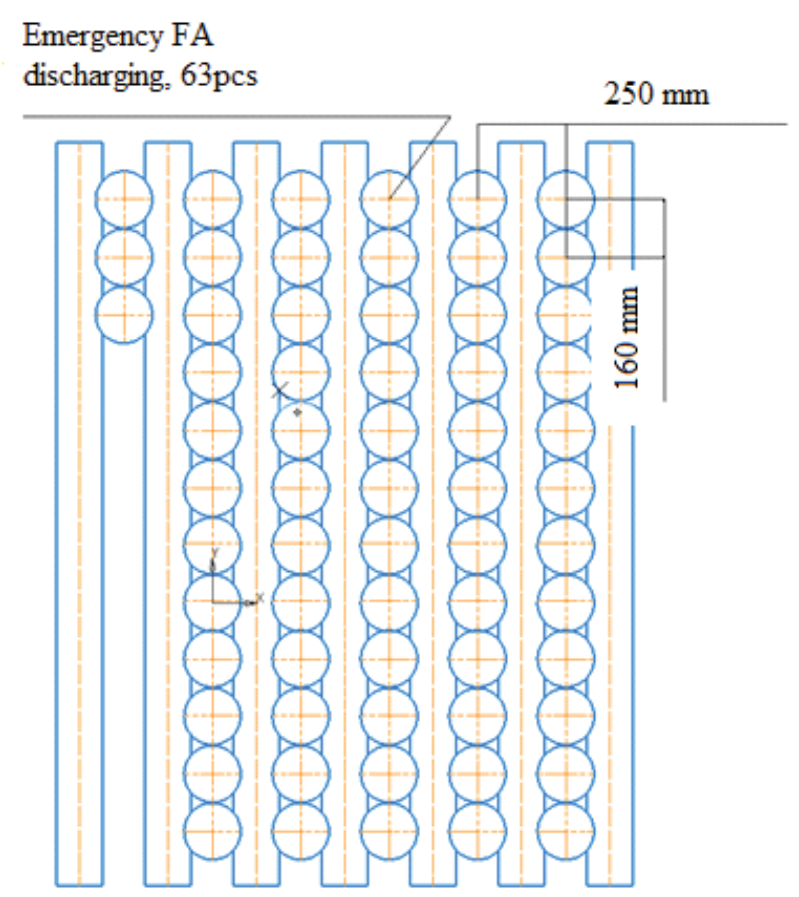

Figure 2. Layout of the emergency FA discharging compartment.

For the computational model, the SFA was represented by a solid cylinder $78 \mathrm{~mm}$ in diameter and $7 \mathrm{~m}$ in height. The sling model consists of two cylindrical parts: one part with a diameter of $78 \mathrm{~mm}$ and a height of $4.93 \mathrm{~m}$ and the other one with a diameter of $36 \mathrm{~mm}$ and a height of $3.57 \mathrm{~m}$. The space between the SFAs in the SFP was filled with water (or water and air when the assembly was partially exposed). For the calculation, the equivalent properties of the SFAs were used. The equivalent properties of the assembly model were set from the condition of equality of the maximum temperature of the SFA model and the fuel element of a real assembly at the same temperature of the outer surface $T_{\text {out }}$ and at the same thermal power of the SFA model and all the fuel elements of a real fuel assembly. In the model with compacted FA storage in the SFP, the heat release corresponded to a maximum power of 1.951 MW (Report 01-41-62-53-TX 2011). In the model under consideration, we took as an assumption a uniform SFA axial power distribution, since the "history" of the operation of the assemblies in the reactor was unknown. For the emergency FA discharging compartment, the heat release is 0.781 MW (Report 01-41-62-53-TX 2011). A model of a spent fuel assembly is shown in Fig. 3 . 


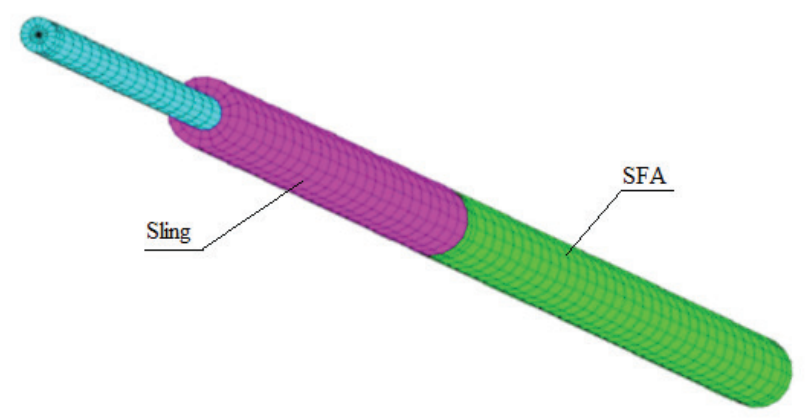

Figure 3. Model of a spent fuel assembly.

\section{Results}

Numerical simulation of the temperature conditions in the SFP emergency discharging compartment is the most acceptable analytical tool, since the experimental study of such situations is problematic. The calculation was carried out using the ANSYS CFX software (ANSYS CFX 2011).

The properties of the materials used for constructing the computational model (fuel, fuel element cladding, stainless steel, water, air) were taken from (Chirkin 1968; Rivkin and Alexandrov 1984; Kirillov et al. 2010; Engineering - Handbook (accessed May 20, 2019), ProfProkat - Handbook of Metals (accessed May 20, 2019)).

The obtained model was used to calculate the temperature conditions in the SFP during compacted SFA storage for a stationary state when forced circulation was stopped. The calculation results showed that even if the SFP was fully filled with water, the water was heated to the boiling point. Natural circulation was hindered due to the rather close arrangement of the SFAs; a significant portion of the heat was transferred by thermal conductivity.

In order to determine the time of water heating to the boiling point, calculations for transient conditions were carried out. It was shown that, when the forced circulation was stopped, the water in the SFP was heated to $90{ }^{\circ} \mathrm{C}$ in $90,700 \mathrm{~s}$ (25.19 hours), and it heated up to the boiling point in $126,500 \mathrm{~s}$, or approximately 35.1 hours (Fig. 4).

For the SFP model, the following options were considered: exposure of the SFAs in the SFP by 20, 25 and

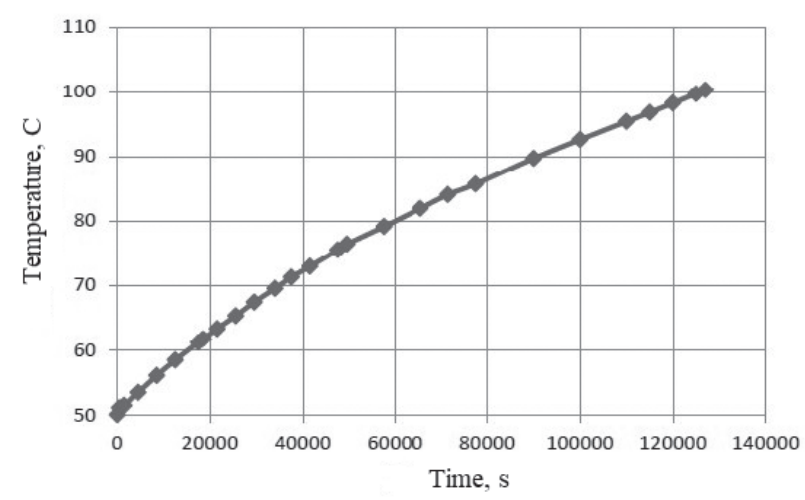

Figure 4. Change in water temperature in the SFP upon termination of forced circulation (compacted storage of SFAs without water loss in the SFP).
$50 \%$, i.e., some of the SFAs are in the water and some are in the air. First, calculations were carried out for stationary conditions in order to determine the onset of the "limit" state, i.e., heating the water to the boiling point or heating the fuel assemblies to $650{ }^{\circ} \mathrm{C}$. The results obtained showed that only when no more than $20 \%$ is exposed, the SFA temperature does not reach the limit value of $650{ }^{\circ} \mathrm{C}$. With greater exposure of the assemblies, the SFA temperature noticeably exceeds the limit values. In all the considered cases, the water temperature reached the boiling point $\left(T_{\text {boil }}=100{ }^{\circ} \mathrm{C}\right)$. The next step was the calculation of transient conditions in order to estimate the time for heating the water in the SFP to the boiling point and heating the SFAS to the temperature of $650{ }^{\circ} \mathrm{C}$.

As expected, the exposed part of the assemblies in the air was heated to a higher temperature as compared to the part in the water. This led to the fact that the upper water layer was heated rather quickly to the boiling point, while the lower layers were at temperatures lower than the saturation temperature. The maximum water temperature in time with partial exposure of the SFAs changed practically according to a linear law, which was a consequence of the accepted assumption of a uniform SFA axial power distribution. This time was approximately 7.5 hours (Fig. 5).

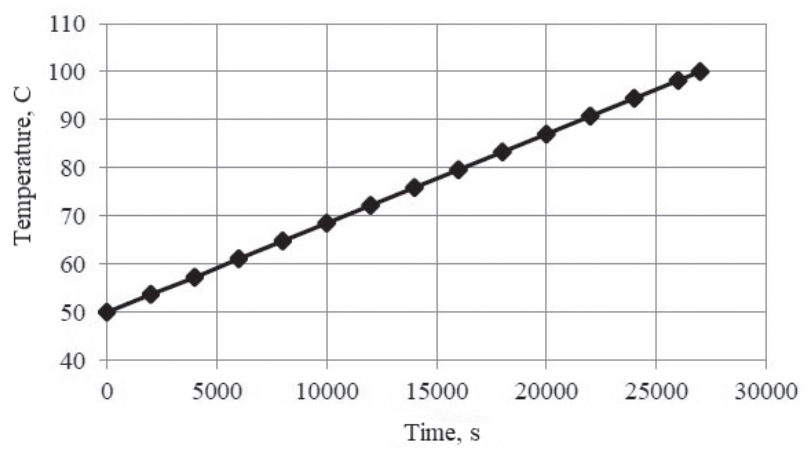

Figure 5. Water heating to the saturation temperature in the SFP (sealed FA storage, partial loss of water with $50 \%$ exposure of the SFAs).

As for the emergency SFA unloading compartment, the time for heating the water to the boiling point and heating the SFAs to $650{ }^{\circ} \mathrm{C}$ was significantly less as compared to the compacted SFA storage compartment. The calculation results showed as follows: with a decrease in the volume of water in the SFP to the level of the SFA heads, the boiling temperature was reached in 2.5 hours; when the SFAs were exposed by $25 \%$, it would take 1.84 hours; and when the SFAs were exposed by $50 \%$, the water would boil in 1.56 hours (Fig. 6). In some of the considered cases, the SFAs were heated to a temperature of $650{ }^{\circ} \mathrm{C}$ faster than the water began to boil.

Figure 7 shows the time-temperature dependence of the SFAs. Thus, for example, when the SFAs were exposed by $50 \%$, their limiting temperature was reached after 1.12 hours, i.e., before the water was heated to the boiling point and, when the SFAs were exposed by $25 \%$, the temperature of $650{ }^{\circ} \mathrm{C}$ could be reached in 2.68 hours, 


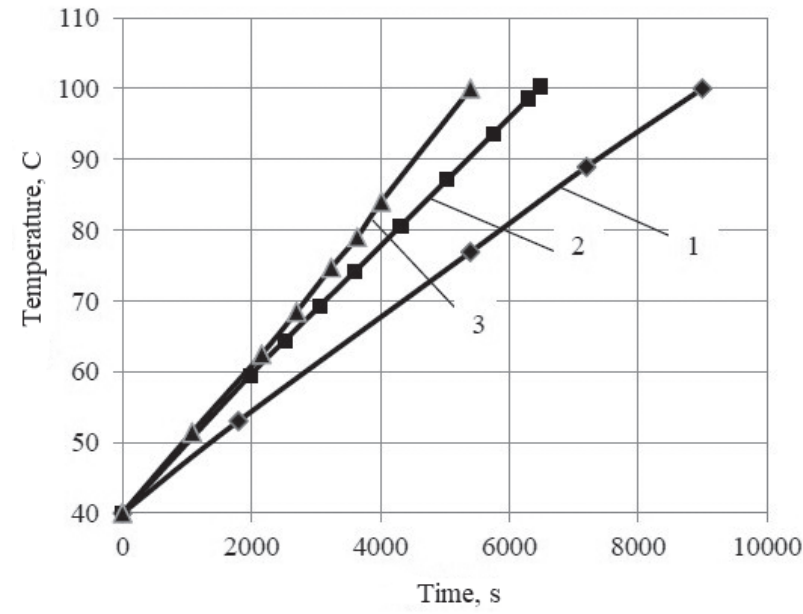

Figure 6. Changes in the water temperature in the emergency FA unloading compartment: 1 - decrease in the water level to the SFA heads; 2 - the SFAs exposed by $25 \% ; 3$ - the SFAs exposed by $50 \%$.

i.e., almost simultaneously with heating the water in the compartment to the boiling point.

\section{Conclusions}

The paper considers the temperature conditions in the spent fuel pool of a power unit with the RBMK-1000 reactor during compacted SFA storage and during emergency SFA unloading. The authors considered options with disturbances in the SFP cooling conditions, including partial loss of water and exposure of SFAs.

The calculations showed that, in the case of compacted SFA storage, when they were exposed no more than by

\section{References}

- Ahn KI, Shin JU, Kim WT (2016) Severe accident analysis of plant-specific spent fuel pool to support a SFP risk and accident management. Annals of Nuclear Energy 89: 70-83. https://doi org/10.1016/j.anucene.2015.11.024

- ANSYS CFX (2011) User's Guide. ANSYS Inc., 368 pp.

- Barto A, Chang JY, Compton K, Esmaili H, Helton D, Murphy A, Nosek A, Pires J, Schofer F, Wagner B (2013) Consequence study of a beyond-design-basis earthquake affecting the spent fuel pool for a U.S. Mark I boiling water reactor. Report SECY-13-0112-Enclosure-1 (ADAMS accession no. ML13256A342), U.S. Nuclear Regulatory Commission, Washington, DC, USA.

- Bernd SJ (2015) Status of the spent fuel in the reactor buildings of Fukushima Daiichi 1-4. Nuclear Engineering and Design 283: 2-7. https://doi.org/10.1016/j.nucengdes.2014.07.007

- Chen SR, Lin WC, Ferng Y-M, Chieng CC, Pei BS (2014) CFD simulating the transient thermal-hydraulic characteristics in a $17 \times 17$ bundle for a spent fuel pool under the loss of external cooling sys-

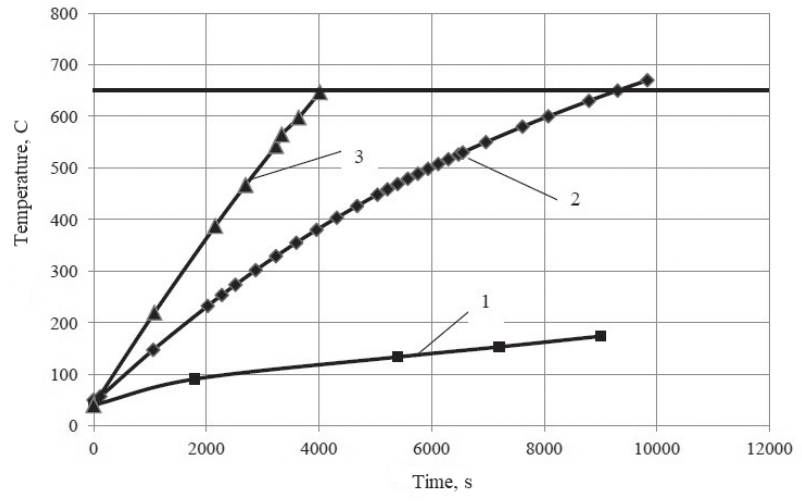

Figure 7. Changes in the SFA temperature in the emergency FA unloading compartment: 1 - decrease in the water level to the SFA heads; 2 - the SFAs exposed by $25 \% ; 3$ - the SFAs exposed by $50 \%$.

$20 \%$, their temperature did not exceed $650{ }^{\circ} \mathrm{C}$, and the water in the pool was heated to the boiling point in approximately 7.5 hours. With greater exposure of the SFAs, the spent assembly itself could be heated to a temperature noticeably higher than $650{ }^{\circ} \mathrm{C}$.

The assessment showed that the time of water heating in the emergency FA unloading compartment decreased from 2.5 hours (with a decrease in the water volume in the SFP to the level of the SFA heads) to 1.56 hours when the fuel assemblies were exposed by $50 \%$. When the SFAs were exposed to $50 \%$, their claddings were heated to $650{ }^{\circ} \mathrm{C}$ in 1.12 hours, i.e., faster than the water was heated to the boiling point.

The results obtained can be considered as an estimate of the time that personnel have to restore the SFP cooling conditions. tem accident. Annals of Nuclear Energy 73: 241-249. https://doi. org/10.1016/j.anucene.2014.06.054

- Cheng-Lun Yu (2018) Numerical study on hydrodynamic and thermal characteristics of spent fuel pool. Annals of Nuclear Energy 119: 139-147. https://doi.org/10.1016/j.anucene.2018.04.042

- Chirkin VS (1968) Thermophysical properties of nuclear materials. Handbook. Moscow. Atomizdat Publ., 484 pp. [in Russian]

- Engineering (2019) Engineering - Handbook. http://fast-const.ru/ articles.php?article_id=20 [accessed May 20, 2019] [in Russian]

- Gauntt RO, Cole RK, Erickson CM, Gido RG, Gasser RD, Rodriguez SB, Yong MF (2000) MELCOR computer code manuals. Report NUREG/CR-6119, U.S. Nuclear Regulatory Commission, Washington, DC, USA.

- Hung T-C, Dhir VK, Pei B-S, Chen Y-S (2013) The development of a three-dimensional transient CFD model for predicting cooling ability of spent fuel pools. Applied Thermal Engineering,50: 496-504. https://doi.org/10.1016/j.applthermaleng.2012.06.042 
- Jäckel B (2013) Spent fuel pool boil down calculations with MELCOR 1.8.6. 2013. In: Fifth European MELCOR User Group Meeting, May 2-3, Stockholm, Sweden.

- Kaliatka A, Ognerubov V, Vileiniškis V, Uspuras E (2013) Analysis of the processes in spent fuel pools in case of loss of heat removal due to water leakage. Science and Technology of Nuclear Installations 3: 1-11. https://doi.org/10.1155/2013/598975

- Kirillov PL, Bobkov VP, Zhukov AV, Yur'ev YuS (2010) Handbook on thermohydraulic calculations in nuclear power industry. Edited by P.L. Kirillov. Vol. 1: Thermohydraulic processes in nuclear power plants. Moscow. IzdAT Publ., 771 pp. [in Russian]

- Ogino M (2012) Analysis of fuel heat-up in a spent fuel pool during a LOCA. 2012. In: Technical Workshop on the Accident of TEPCO's Fukushima Daiichi NPS, July 23-24, Tokyo, Japan.

- Partmann C, Schuster C, Hurtado A (2018) Experimental investigation of the thermal hydraulics of a spent fuel pool under loss of active heat removal conditions. Nuclear Engineering and Design 330 480-487. https://doi.org/10.1016/j.nucengdes.2018.02.023
- ProfProkat (2019) ProfProkat - Handbook of Metals. Available at: http://profprokat.ru/content/view/167/8/ [accessed May 20, 2019] [in Russian]

- Report 01-41-62-53-TX (2011) Calculation of the temperature regime of water in the SFP and justification of explosion safety when handling uranium-erbium fuel. Moscow. OJSC Atomenergoproekt Publ. [in Russian]

- Rivkin SL, Alexandrov AA (1984) Thermodynamic properties of water and water steam. Handbook. Moscow. Energoatomizdat Publ., 80 pp. [in Russian]

- Song JH, Kim TW (2014) Severe accident issues raised by the Fukushima accident and improvements suggested. Nuclear Engineering and Technology 46: 207-216. https://doi.org/10.5516/ NET.03.2013.079

- Wang D, Gauld IC, Yoder G, Ott LJ (2012) Study of Fukushima Daiichi nuclear power station unit 4 spent-fuel pool. $\mathrm{Nu}$ clear Technology 180: 205-215. https://doi.org/10.13182/ NT12-A14634 